\title{
Smoked cannabis for chronic neuropathic pain: a randomized controlled trial
}

\author{
Mark A. Ware MBBS, Tongtong Wang PhD, Stan Shapiro PhD, Ann Robinson RN, Thierry Ducruet MSc, \\ Thao Huynh MD, Ann Gamsa PhD, Gary J. Bennett PhD, Jean-Paul Collet MD PhD
}

Previously published at www.cmaj.ca

See related commentary by McQuay at www.cmaj.ca

\section{ABSTRACT}

Background: Chronic neuropathic pain affects $1 \%-2 \%$ of the adult population and is often refractory to standard pharmacologic treatment. Patients with chronic pain have reported using smoked cannabis to relieve pain, improve sleep and improve mood.

Methods: Adults with post-traumatic or postsurgical neuropathic pain were randomly assigned to receive cannabis at four potencies $(0 \%, 2.5 \%, 6 \%$ and $9.4 \%$ tetrahydrocannabinol) over four 14-day periods in a crossover trial. Participants inhaled a single 25-mg dose through a pipe three times daily for the first five days in each cycle, followed by a nine-day washout period. Daily average pain intensity was measured using an 11-point numeric rating scale. We recorded effects on mood, sleep and quality of life, as well as adverse events.

Results: We recruited 23 participants (mean age 45.4 [standard deviation 12.3] years, 12 women [52\%]), of whom 21 completed the trial. The average daily pain intensity, measured on the 11-point numeric rating scale, was lower on the prespecified primary contrast of $9.4 \%$ v. $0 \%$ tetrahydrocannabinol (5.4 v. 6.1 , respectively; difference $=0.7,95 \%$ confidence interval $[\mathrm{Cl}]$ 0.02-1.4). Preparations with intermediate potency yielded intermediate but nonsignificant degrees of relief. Participants receiving $9.4 \%$ tetrahydrocannabinol reported improved ability to fall asleep (easier, $p=0.001$; faster, $p<0.001$; more drowsy, $p=0.003$ ) and improved quality of sleep (less wakefulness, $p=0.01$ ) relative to $0 \%$ tetrahydrocannabinol. We found no differences in mood or quality of life. The most common drug-related adverse events during the period when participants received $9.4 \%$ tetrahydrocannabinol were headache, dry eyes, burning sensation in areas of neuropathic pain, dizziness, numbness and cough.

Conclusion: A single inhalation of $25 \mathrm{mg}$ of $9.4 \%$ tetrahydrocannabinol herbal cannabis three times daily for five days reduced the intensity of pain, improved sleep and was well tolerated. Further long-term safety and efficacy studies are indicated. (International Standard Randomised Controlled Trial Register no. ISRCTN68314063)

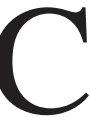
hronic neuropathic pain has a prevalence of $1 \%-2 \%$, and treatment options are limited. ${ }^{2}$ Pharmacotherapy includes anticonvulsants, antidepressants, opioids and local anesthetics, ${ }^{3,4}$ but responses vary and side effects limit compliance.
Cannabis sativa has been used to treat pain since the third millennium BC..$^{5}$ An endogenous pain-processing system has been identified, mediated by endogenous cannabinoid ligands acting on specific cannabinoid receptors. ${ }^{6}$ These findings, coupled with anecdotal evidence of the analgesic effects of smoked cannabis, ${ }^{7}$ support a reconsideration of cannabinoid agents as analgesics.

Oral cannabinoids such as tetrahydrocannabinol, cannabidiol and nabilone have, alone and in combination, shown efficacy in central ${ }^{8.9}$ and peripheral ${ }^{10}$ neuropathic pain, rheumatoid arthritis ${ }^{11}$ and fibromyalgia. ${ }^{12}$

The analgesic effects of smoked cannabis remain controversial, although it is used by $10 \%-15 \%$ of patients with chronic noncancer pain ${ }^{13}$ and multiple sclerosis. ${ }^{14}$ Clinical trials are needed to evaluate these effects, given that the risks and benefits of inhaled cannabinoids may differ from oral agents. To date, three small clinical trials of the analgesic efficacy of smoked cannabis have been reported. ${ }^{15-17}$ All studies were conducted in residential laboratories, and participants smoked multiple doses of the drug at each time point. No study adequately reported data related to adverse events.

We conducted a clinical trial using a standardized single-dose delivery system to explore further the safety and efficacy of smoked cannabis in outpatients with chronic neuropathic pain.

\section{Methods}

\section{Participants}

The study was approved by the McGill University Health Centre Research Ethics Committee, and all participants gave written informed consent. Participants were recruited at the McGill University Health Centre.

Those eligible were men and women aged 18 years or older with neuropathic pain of at least three months in duration caused by trauma or surgery, with allodynia or hyperalgesia,

From the Department of Anesthesia (Ware), the Department of Family Medicine (Ware), the Department of Epidemiology, Biostatistics and Occupational Health (Wang, Shapiro), the Department of Medicine (Huynh) and the Alan Edwards Centre for Research on Pain (Gamsa, Bennett), McGill University, Montréal, Que.; Boreal Primum (Robinson, Ducruet), Montréal, Que.; and the Centre for Applied Health Research and Evaluation (Collet), University of British Columbia, Vancouver, BC

CMAJ 2010. DOI:10.1503/cmaj.091414 
and with an average weekly pain intensity score greater than 4 on a $10-\mathrm{cm}$ visual analogue scale. Participants had a stable analgesic regimen and reported not having used cannabis during the year before the study (Appendix 1, available at www .cmaj.ca/cgi/content/full/cmaj.091414/DC1). Potential participants had to have normal liver function (defined as aspartate aminogransferase less than three times normal), normal renal function (defined as a serum creatinine level $<133 \mu \mathrm{mol} / \mathrm{L}$ ), normal hematocrit (>38\%) and a negative result on $\beta$ human chorionic gonadotropin pregnancy test (if applicable). Women of child-bearing potential consented to use adequate contraception during the study and for three months afterward.

Exclusion criteria were pain due to cancer or nociceptive causes, presence of significant cardiac or pulmonary disease, current substance abuse or dependence (including abuse of or dependence on cannabis), history of psychotic disorder, current suicidal ideation, pregnancy or breastfeeding, participation in another clinical trial within 30 days of enrolment in our trial, and ongoing insurance claims.

\section{Study design}

We used a randomized, double-blind, placebo-controlled, fourperiod crossover design. Each period was 14 days in duration, beginning with five days on the study drug followed by a nineday washout period. Eligible participants were randomized to a sequence of treatment periods based on a Latin square design.

Cannabis was obtained from Prairie Plant Systems Inc. (Saskatoon, Sask.) and the United States National Institute of Drug Abuse. Prairie Plant Systems Inc. blended cannabis flowers and leaves to prepare three different potencies of active drug $(2.5 \%, 6.0 \%$ and $9.4 \%$ tetrahydrocannabinol). The US National Institute of Drug Abuse used ethanolic extraction of cannabinoids to prepare the $0 \%$ tetrahydrocannabinol product. Intermediate doses $(2.5 \%$ and $6.0 \%$ tetrahydrocannabinol) were used to increase the likelihood of successful blinding. Doses of $25 \mathrm{mg}( \pm 1 \mathrm{mg})$ were prepared in opaque gelatin capsules by the study pharmacist. A panel of nine independent personnel examined the appearance of the four cannabis preparations and found no association between estimated and true potency (data not shown).

Cannabis doses were delivered as single smoked inhalations using a titanium pipe (RayDiaTor, Mori Designs, Auburn, WA, USA). The first dose of each period was selfadministered under observation in a ventilated room. For dose delivery, one capsule of the assigned potency was opened and the cannabis tipped into the bowl of the pipe. Participants were instructed to inhale for five seconds while the cannabis was lit, hold the smoke in their lungs for ten seconds, and then exhale. The beginning of inhalation was recorded as the onset of the exposure. Subsequent doses were self-administered in the same manner three times daily at home for the first five days of each period.

Routine medications were continued throughout the trial. Use of breakthrough analgesia (acetaminophen) was allowed.

\section{Study protocol}

The study nurse explained the study to each participant, sought signed informed consent, obtained a medical history and performed a chart review. The study physician conducted a physical examination. Urinary drug screening was performed. Participants were contacted by telephone on three occasions during the first five days of the screening phase to calculate a baseline average pain score. A psychological evaluation was conducted by a clinical psychologist.

On the first day of each period, participants were followed for three hours. Vital signs and ratings of pain, "high," relaxation, stress, happiness and heart rate were recorded, and blood was collected for tetrahydrocannabinol assays. On days one and five of each study period, blood was collected for hematologic and biochemical analyses. At the end of their first visit, participants were given four labelled containers for urine collection and 13 cannabis doses for the five days of treatment.

During the first five days of each period, participants were contacted daily by telephone to administer questionnaires on pain intensity, sleep, medication and adverse effects. Participants collected early morning urine samples daily. They returned on day five to return the urine samples, to undergo urinary and blood tests, and to complete questionnaires on pain quality, mood, quality of life and assessments of potency. At the end of the study, participants completed final adverse event reports and potency assessments. Participants were advised not to drive a vehicle or operate heavy machinery while under the influence of the study drug.

\section{Outcome measures}

Outcome measures were selected following published recommendations for clinical trials of chronic pain. ${ }^{18}$ Pain intensity was measured using an 11-item numeric rating scale, with "no pain" and "worst pain possible" as anchors. The numeric rating scale was administered once daily for present, worst, least and average pain intensity during the previous 24 hours. As per protocol, the average pain intensity score over the five days on study drug constituted the primary outcome. Acute effects on pain intensity were measured using a $100-\mathrm{mm}$ visual analogue scale. Pain quality was assessed using the McGill Pain Questionnaire. ${ }^{19}$ Sleep was assessed using the Leeds Sleep Evaluation Questionnaire. ${ }^{20}$ The short-form Profile of Mood States was used to examine mood effects. ${ }^{21}$ Quality of life was assessed using the EQ-5D health outcome instrument. ${ }^{22}$ The items "high," "relaxed," "stressed," and "happy" were measured using a 100-mm visual analogue scale $(0=$ not at all, $10=$ extremely $){ }^{23-25}$ Potency assessments were conducted by asking participants on the fifth day of each period to guess which potency they had received. At the end of the trial, participants were asked to guess the order in which they received the treatments. Standard assays for plasma tetrahydrocannabinol assays were used (Appendix 1).

\section{Statistical analysis}

Our primary hypothesis was that smoked cannabis containing $9.4 \%$ tetrahydrocannabinol is superior to $0 \%$ tetrahydrocannabinol in reducing average pain intensity. The comparison of within-patient average weekly pain intensity when assigned 9.4\% tetrahydrocannabinol cannabis compared with placebo was the contrast of primary interest. A sample size of 32 patients was targeted assuming a within-patient difference 
of $10 \mathrm{~mm}^{26}$ in the primary outcome between active and placebo drug, on a $100 \mathrm{~mm}$ scale, with a standard deviation of $20 \mathrm{~mm}$, and with $80 \%$ power and 5\% significance.

A generalized linear model including drug, period and firstorder carryover effects was fitted. If the carryover effect or period effect was not significant, then a reduced model was refitted. Nine-five per cent confidence intervals were generated. Significance tests were performed at a 5\% level. An identical procedure to that described above for the primary outcome was performed to assess the secondary outcomes, including the McGill Pain Questionnaire, the Leeds Sleep Evaluation Questionnaire, the Profile of Mood States, and EQ5D. Statistical procedures for day one assessments and EQ-5D analyses are shown in Appendix 1. Data from all randomized participants were included in all safety and efficacy analyses.

All reported adverse events were classified according to severity, seriousness and relationship to the study drug. An independent data-monitoring committee monitored the safetyrelated aspects of the trial.

\section{Regulatory considerations}

In conducting the study, we followed the Good Clinical Practice guidelines of the International Conference on Harmonisation of Technical Requirements for Registration of Pharmaceuticals for Human Use. ${ }^{27}$ The trial was registered with the International Standard for Randomised Controlled Trials Register (ISRCTN683140063).

\section{Results}

\section{Participants}

We screened 116 potential participants over a 30-month period (August 2003 to January 2006), of whom 93 were ineligible. Twenty-three participants underwent random assignment to treatment, of whom 21 completed all four cycles. Two participants withdrew within the first five days of the study; one (who was receiving placebo at the time) withdrew because of a positive result on urinary screening for cannabinoid and the other (who was receiving 6\% tetrahydrocannabinol at the time) because of increased pain (Figure 1). Demographic and baseline pain characteristics of participants are shown in Table 1.

\section{Primary outcome}

We found no evidence of significant carryover or period effects for any outcome. The average daily pain intensity was significantly lower on $9.4 \%$ tetrahydrocannabinol cannabis (5.4) than on $0 \%$ tetrahydrocannabinol (6.1) $(p=0.023$; difference $=0.7,95 \%$ CI 0.02-1.4). All pairwise differences between groups are shown with $95 \%$ CIs in Table 2. The average daily pain scores for each level of tetrahydrocannabinol, along with other secondary outcomes, are shown in Table 2.

\section{Secondary outcomes}

There was a trend toward improvement in all outcomes with increasing tetrahydrocannabinol content (Table 3). Participants using 9.4\% tetrahydrocannabinol cannabis reported significantly more drowsiness and reported getting to sleep more easily, faster and with fewer periods of wakefulness compared with those using placebo $(p<0.05)$. Anxiety and depression were improved in the $9.4 \%$ tetrahydrocannabinol

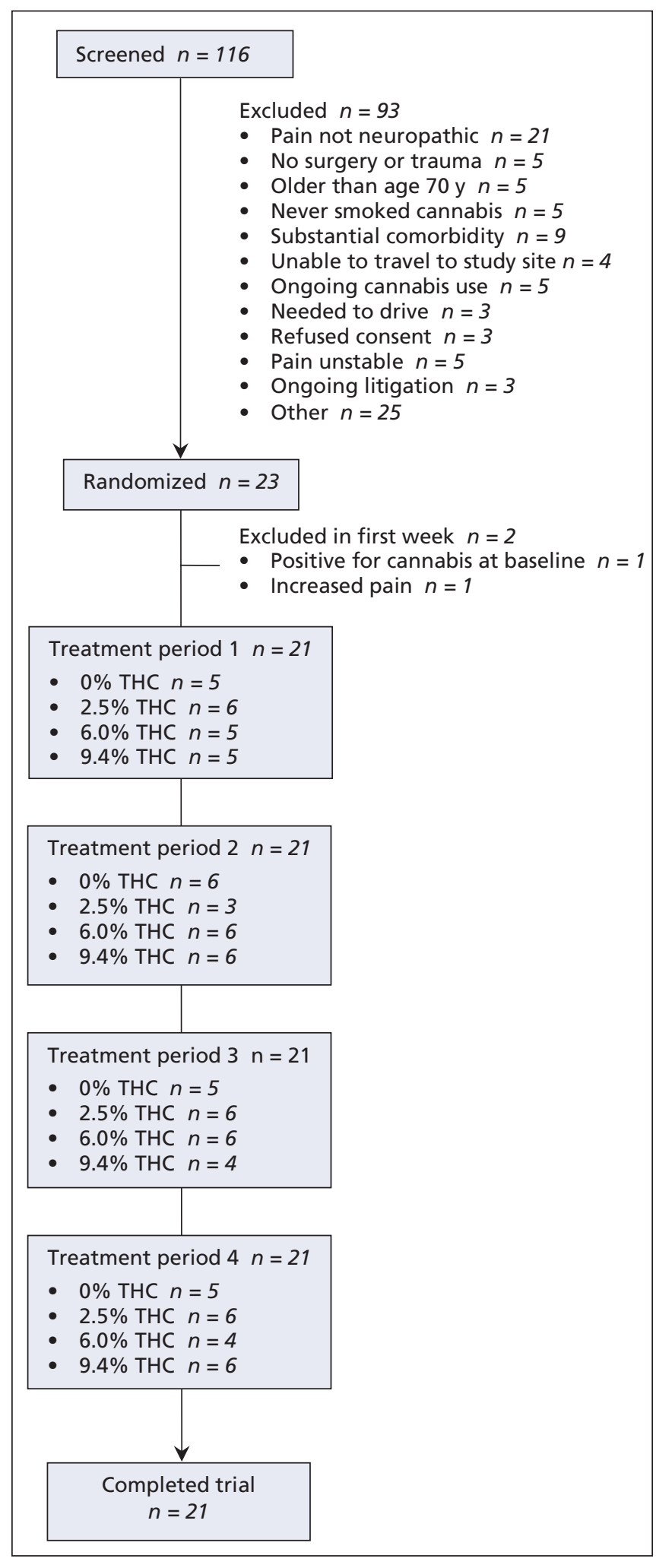

Figure 1: Flow of patients through the randomized controlled trial. 
Table 1: Demographic and baseline characteristics of participants

\begin{tabular}{|c|c|}
\hline Characteristic & $\begin{array}{c}\text { No. }(\%) \text { of subjects* } \\
n=23\end{array}$ \\
\hline \multicolumn{2}{|l|}{ Age, yr } \\
\hline Mean (SD) & $45.4(12.3)$ \\
\hline Range & $25-77$ \\
\hline \multicolumn{2}{|l|}{ Sex } \\
\hline Male & $11(47.8)$ \\
\hline Female & $12(52.2)$ \\
\hline \multicolumn{2}{|l|}{ Education } \\
\hline Primary or elementary & $1(4.3)$ \\
\hline Secondary or high school & $8(34.8)$ \\
\hline University or college & $14(60.9)$ \\
\hline \multicolumn{2}{|l|}{ Employment status } \\
\hline Full-time or part-time & $4(17.4)$ \\
\hline Retired & $2(8.7)$ \\
\hline Short-term disability or disabled & $14(60.9)$ \\
\hline Other & $3(13.0)$ \\
\hline \multicolumn{2}{|l|}{ Medications } \\
\hline Opioids & $14(61)$ \\
\hline Antidepressants & $12(52)$ \\
\hline Anticonvulsants & $10(43)$ \\
\hline NSAIDS & $10(43)$ \\
\hline \multicolumn{2}{|l|}{ Tobacco use } \\
\hline Never smoked & $8(34.8)$ \\
\hline Current smoker & $9(39.1)$ \\
\hline Ex-smoker & $6(26.1)$ \\
\hline \multicolumn{2}{|l|}{ Ever used alcohol } \\
\hline Yes & $14(60.9)$ \\
\hline No & $9(39.1)$ \\
\hline \multicolumn{2}{|l|}{ Ever used cannabis } \\
\hline Yes & $18(81.8)$ \\
\hline No & $4(18.2)$ \\
\hline \multicolumn{2}{|l|}{ Average daily pain at baseline } \\
\hline Mean (SD) & $6.89(1.37)$ \\
\hline Range & $4.0-9.2$ \\
\hline
\end{tabular}

Note: NSAIDS = nonsteroidal anti-inflammatory drugs, SD = standard deviation.

*Unless otherwise indicated. group compared with placebo on the EQ-5D subscale $(p<0.05)$. No significant differences were noted on the Profile of Mood States. No difference in the "high," "happy," "relaxed" or "stressed" scores on the visual analogue scale were observed between tetrahydrocannabinol potencies.

A total of 248 mild and six moderate adverse events (fall, ${ }^{2}$ increased pain, ${ }^{1}$ numbness, ${ }^{1}$ drowsiness ${ }^{1}$ and pneumonia ${ }^{1}$ ) were reported during the trial (Table 4). No serious or unexpected adverse events were reported. The total number of adverse events and the number of participants reporting at least one adverse event increased with tetrahydrocannabinol potency. The most frequent drug-related adverse events reported in the group receiving $9.4 \%$ tetrahydrocannabinol were headache, dry eyes, burning sensation, dizziness, numbness and cough. Feeling "high" and euphoria were reported once in each of the $2.5 \%, 6 \%$ and $9.4 \%$ tetrahydrocannabinol periods. No significant changes in vital signs, heart-rate variability, hematological, biochemistry or renal function blood tests were detected.

On day five of the first cycle, 1 of 5 participants (20\%) assigned to placebo correctly identified this assignment, while 9 of the 16 participants (56\%) who received placebo during later cycles did so. Of the 5 participants administered $9.4 \%$ tetrahydrocannabinol in their first cycle, none correctly identified this assignment, while 10 of 16 patients (63\%) did so during later cycles. At the end of the trial, 16 (76\%) of the participants were able to correctly identify the $9.4 \%$ tetrahydrocannabinol period and $13(62 \%)$ were able to identify the $0 \%$ tetrahydrocannabinol period, whereas the $6 \%$ tetrahydrocannabinol period was identified by 8 participants (38\%) and the $2.5 \%$ period by $7(33 \%)$.

Compliance with the study was excellent, and all dispensed capsules were returned. With the exception of one participant who withdrew from the study, there were no positive urine tetrahydrocannabinol tests during the $0 \%$ tetrahydrocannabinol period or on any day one before exposure (Appendix 1).

Plasma tetrahydrocannabinol assays revealed dose-response pharmacokinetics (Figure 2) and confirmed that participants did not use cannabis during placebo phases (Appendix 1).

Pharmacy dispensing was satisfactory. No legal issues arose during the study and there were no reports or allegations of diversion of the study drug.

\section{Discussion}

We found that $25 \mathrm{mg}$ herbal cannabis with $9.4 \%$ tetrahydrocannabinol, administered as a single smoked inhalation three

Table 2: Pairwise comparisons of the effects of four potencies of smoked cannabis on average daily pain

\begin{tabular}{|c|c|c|c|c|c|c|c|c|}
\hline \multirow{3}{*}{$\begin{array}{l}\text { Potency, } \\
\% \text { of THC } \\
0\end{array}$} & \multicolumn{8}{|c|}{ Potency, $\%$ of THC, mean difference $(95 \% \mathrm{Cl})$} \\
\hline & \multicolumn{2}{|r|}{0} & \multicolumn{2}{|r|}{2.5} & \multicolumn{2}{|r|}{6.0} & \multicolumn{2}{|c|}{9.4} \\
\hline & - & - & - & - & - & - & - & - \\
\hline 2.5 & -0.13 & $(-0.83$ to 0.56$)$ & - & - & - & - & - & - \\
\hline 6.0 & -0.09 & $(-0.78-0.60)$ & 0.04 & $(-0.64$ to 0.73$)$ & - & - & - & - \\
\hline 9.4 & -0.71 & $(-1.40$ to -0.02$)$ & -0.58 & $(-1.27$ to 0.11$)$ & -0.63 & $(-1.30$ to 0.06$)$ & - & - \\
\hline
\end{tabular}

Note: $\mathrm{Cl}=$ confidence interval, $\mathrm{THC}=$ tetrahydrocannabinol 
Table 3: Effects of smoked cannabis and secondary outcomes, by potency of tetrahydrocannabinol (THC) received

\begin{tabular}{|c|c|c|c|c|c|}
\hline Outcome & \multicolumn{5}{|c|}{ Potency of THC, \%; outcome measure, mean (SD)* } \\
\hline Average daily pain & $6.1(1.6)$ & $5.9 \quad(1.9)$ & $6.0(1.8)$ & 5.4 & $(1.7) \dagger$ \\
\hline Highest daily pain & 7.1 (1.4) & $7.0 \quad(1.6)$ & $7.0 \quad(1.5)$ & 6.5 & $(1.6)$ \\
\hline Lowest daily pain & $5.1(2.1)$ & $5.0 \quad(2.4)$ & $4.8 \quad(2.4)$ & 4.4 & $(2.2)$ \\
\hline Sensory & $17.2(10.5)$ & $17.1(9.9)$ & $14.8(9.2)$ & 15.6 & $(8.7)$ \\
\hline Affective & $3.5(3.0)$ & $3.8 \quad(3.6)$ & $3.3(3.4)$ & 3.0 & $(3.1)$ \\
\hline Evaluative & $2.2(1.5)$ & $2.8 \quad(1.3)$ & 2.1 (1.5) & 1.7 & $(1.5)$ \\
\hline Miscellaneous & $6.2(4.3)$ & $6.8 \quad(4.4)$ & $5.5 \quad(2.9)$ & 4.5 & $(3.6)$ \\
\hline Total score & $29.1(17.0)$ & $30.4(18.1)$ & $25.8(14.5)$ & 24.8 & $(14.7)$ \\
\hline Harder - easier than usual & $5.4(1.5)$ & $5.5 \quad(1.6)$ & $6.1 \quad(1.5)$ & 6.8 & $(1.8) \dagger$ \\
\hline Slower - faster than usual & $5.3(1.3)$ & $5.6(1.4)$ & $6.2 \quad(1.7)$ & 6.9 & $(1.7) \dagger$ \\
\hline Less - more drowsy than usual & $5.3(1.1)$ & $5.9 \quad(1.4)$ & $5.7 \quad(1.3)$ & 6.6 & $(1.5) \dagger$ \\
\hline \multicolumn{6}{|l|}{ Quality of sleep } \\
\hline More restless - more restful & $5.5(1.6)$ & $5.4 \quad(1.7)$ & $5.9 \quad(2.0)$ & 6.5 & $(2.1)$ \\
\hline More - less period wakefulness than usual & $5.3(1.5)$ & 5.0 & $5.5(1.7)$ & 6.3 & $(1.8) \dagger$ \\
\hline \multicolumn{6}{|l|}{ Awakening this morning } \\
\hline More difficult - easier & $4.6(1.2)$ & $4.4 \quad(0.8)$ & $4.7 \quad(1.4)$ & 4.8 & $(1.0)$ \\
\hline Took longer — shorter & $4.4 \quad(0.8)$ & $4.4 \quad(0.9)$ & $1.7 \quad(1.1)$ & 5.0 & $(1.0)$ \\
\hline \multicolumn{6}{|l|}{ Feeling on waking-up } \\
\hline Mobility, no. (\%) & $10(48)$ & $11(52)$ & $11(52)$ & & (55) \\
\hline Self-care, no. (\%) & $14(67)$ & $12(57)$ & $15(71)$ & & (70) \\
\hline Usual activities, no. (\%) & $3(14)$ & $3(14)$ & $4(19)$ & & (25) \\
\hline Pain or discomfort, no. (\%) & $11(52)$ & $10(48)$ & $14(67)$ & & (75) \\
\hline Anxiety or depression, no. (\%) & $4(19)$ & $5(23)$ & $7(33)$ & & $(45) \dagger$ \\
\hline State of health, no. (\%) & $3(14)$ & $2(9)$ & $4(19)$ & & (35) \\
\hline State of health (VAS) & $54.1(19.5)$ & $48.6(18.9)$ & $52.9(22.0)$ & 56.3( & (20.4) \\
\hline \multicolumn{6}{|l|}{ Profile of Mood States (POMS)ף } \\
\hline Depression & $10.6(6.5)$ & $10.4(6.7)$ & $9.3(6.6)$ & 9.4 & $(5.7)$ \\
\hline Vigour & $7.3(4.3)$ & $7.3 \quad(5.4)$ & $6.2(4.6)$ & 8.0 & $(4.6)$ \\
\hline Anger & $9.2(7.0)$ & $7.7 \quad(6.3)$ & 7.9 (7.6) & 6.5 & $(6.0)$ \\
\hline Tension & $8.5 \quad(5.1)$ & $9.3 \quad(4.6)$ & $9.0 \quad(5.6)$ & 7.2 & $(5.2)$ \\
\hline Confusion & $6.3(3.7)$ & $6.7 \quad(4.0)$ & $6.0 \quad(4.3)$ & 5.7 & $(4.1)$ \\
\hline Fatigue & $11.9(4.1)$ & $11.1 \quad(5.0)$ & 11.1 (4.8) & 10.5 & $(5.0)$ \\
\hline Total mood disturbance & $39.1(22.7)$ & $38.0(24.5)$ & $36.9(25.9)$ & 31.2 & (22.4) \\
\hline
\end{tabular}

Note: $\mathrm{EQ}-5 \mathrm{D}=$ health outcome instrument, ${ }^{22} \mathrm{SD}=$ standard deviation, VAS = visual analog scale.

*Unless indicated otherwise.

t $p<0.05$ for the comparison with $0 \%$ THC.

fHigher scores indicate improved sleep parameters.

§Data are presented as a proportion of subjects reporting the most favourable responses; thus, a higher proportion suggests a better health outcome.

IWith the exception of vigour, lower scores represent better mood. 
Table 4: Adverse events reported during the study, by potency of tetrahydrocannabinol (THC) (part 1 of 2)

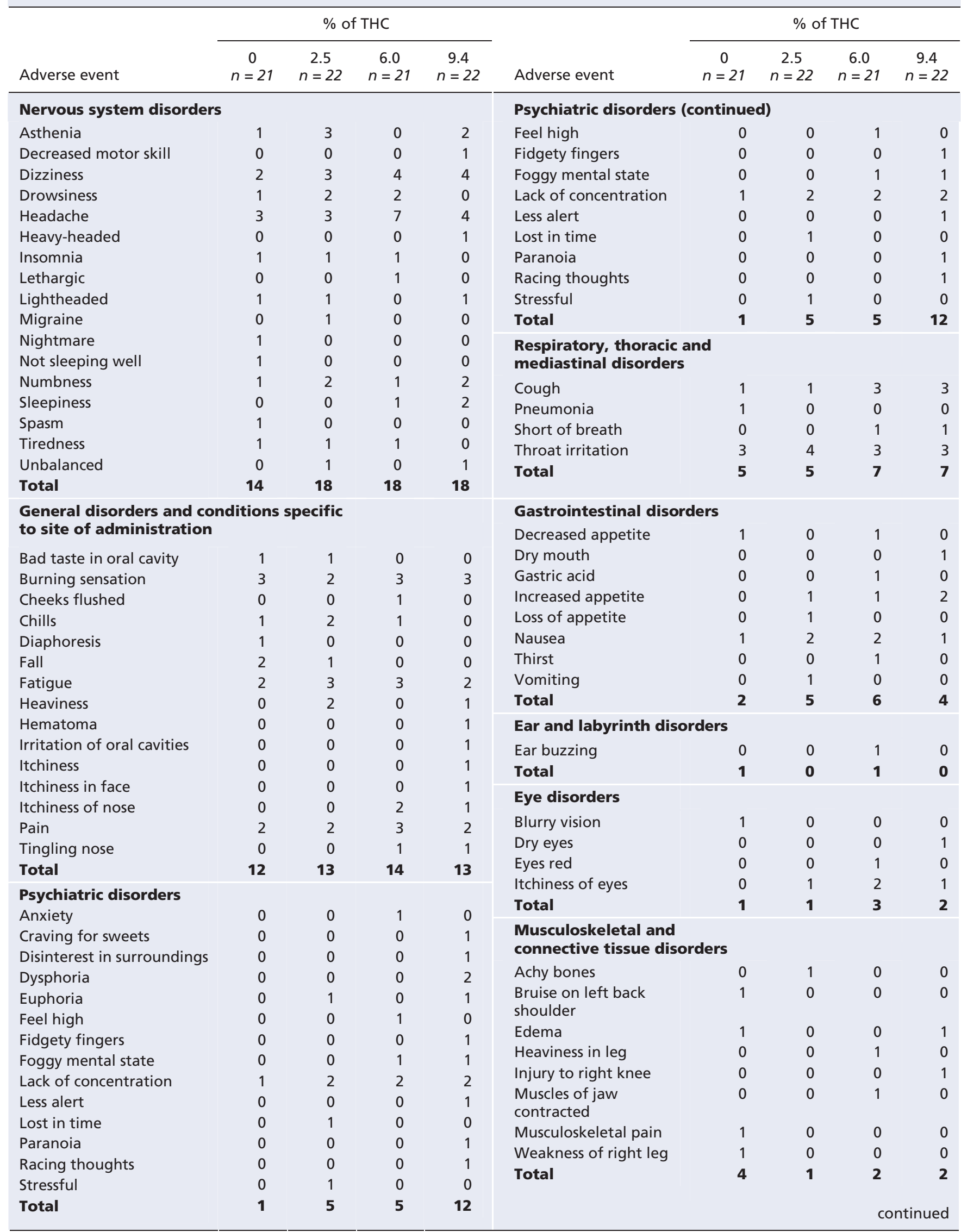


Table 4: Adverse events reported during the study, by potency of tetrahydrocannabinol (THC) (part 2 of 2)

\begin{tabular}{lcccc}
\hline & \multicolumn{4}{c}{$\%$ of THC } \\
\cline { 2 - 5 } & 0 & 2.5 & 6.0 & 9.4 \\
\cline { 2 - 5 } Adverse event & $n=21$ & $n=22$ & $n=21$ & $n=22$ \\
\hline $\begin{array}{l}\text { Infections and infestations } \\
\text { Fever }\end{array}$ & 0 & 1 & 0 & 0 \\
Total & $\mathbf{0}$ & $\mathbf{1}$ & $\mathbf{0}$ & $\mathbf{0}$ \\
\hline $\begin{array}{l}\text { Renal and urinary } \\
\text { disorders }\end{array}$ & & & & \\
$\begin{array}{l}\text { Difficulty voiding } \\
\text { Total }\end{array}$ & 0 & 1 & 0 & 0 \\
\hline $\begin{array}{l}\text { Disorders of skin and } \\
\text { subcutaneous tissue } \\
\text { Rash }\end{array}$ & $\mathbf{0}$ & $\mathbf{1}$ & $\mathbf{0}$ & $\mathbf{0}$ \\
Total & 0 & & & \\
\hline $\begin{array}{l}\text { Surgical and medical } \\
\text { procedures }\end{array}$ & $\mathbf{0}$ & $\mathbf{0}$ & $\mathbf{0}$ & $\mathbf{1}$ \\
$\begin{array}{l}\text { Minor surgery } \\
\text { Total }\end{array}$ & 1 & & & \\
\hline Total adverse events & $\mathbf{4 6}$ & $\mathbf{6 1}$ & $\mathbf{6 5}$ & $\mathbf{8 2}$ \\
\hline
\end{tabular}

Note: THC $=$ tetrahydrocannabinol.

times daily for five days, significantly reduced average pain intensity compared with a $0 \%$ tetrahydrocannabinol cannabis placebo in adult participants with chronic post-traumatic or postsurgical neuropathic pain. We found significant improvements in measures of sleep quality and anxiety. We have shown the feasibility of a single-dose delivery method for smoked cannabis, and that blinding participants to treatment allocation is possible using this method.

The mean reduction in pain (0.7) from 6.1 to 5.4 on a $10-\mathrm{cm}$ scale that we detected in this study is modest when compared with that from other drugs for chronic neuropathic pain, such as gabapentin (1.2) and pregabalin (1.3). ${ }^{28,29}$ However, our study involved participants with refractory pain for which conventional therapies had failed, and this characteristic may have limited the potential for findings of a larger pain reduction.

The effects of cannabinoids on sleep are recognized. ${ }^{7.9}$ The consistent trend toward improvement in all other outcomes for $9.4 \%$ tetrahydrocannabinol compared with placebo in our trial suggests that the reported effects on pain, mood and sleep may have been part of an overall improvement in many aspects of patients' conditions.

\section{Limitations and strengths}

There were several limitations to this trial. The number of participants recruited was smaller than planned, owing to delays in obtaining licences, approvals and the study drug, and to restrictive criteria for eligibility. Most of our participants had prior experience with cannabis, which had been an early ethics requirement; none was using cannabis at the time of enrolment and they were not "experienced" users, so that the lessons learned would be applicable to naive users of medical cannabis. The use of small, fixed doses with a short trial duration may have reduced the effect size. We used a low dose to minimize exposure to smoke and to reduce psychoactive effects. Previous work has shown that a single dose of 0.4 $\mathrm{mg} / \mathrm{kg}$ can be inhaled in a single lungful from a pipe, ${ }^{24,30}$ which for a $70-\mathrm{kg}$ person approximates to $25 \mathrm{mg}$ per dose. The frequency of dosing was based on a duration of action of inhaled tetrahydrocannabinol of two to three hours ${ }^{31}$ and was administered three times daily. We used a fixed dosing schedule because the study was too short to allow dose titration and we wanted the tetrahydrocannabinol potency to be the only difference between cycles. Finally, the highest tetrahydrocannabinol-content cannabis $(9.4 \%)$ legally available at the time of the study was used. Additional studies with higher potencies and flexible dosing strategies are needed to explore dose-response effects.

With respect to our analysis, we are aware of issues surrounding the use of early tests for carryover effects. However, examination of pain scores during the washout period showed that the washout was adequate (data not shown), and therefore we believe our approach was appropriate.

Our trial had several important strengths, including a credible placebo, good compliance and good safety reporting. Finding a suitable placebo for smoked cannabis is not a trivial issue. During protocol reviews, it was stated that participants smoking cannabis would immediately know, based on the acute psychoactive effects, whether they had received active drug; however, our results do not support this view. Instead, our data suggest that short-term placebo-controlled trials of smoked cannabis are feasible.

The safety of smoked cannabis is a concern for patients and

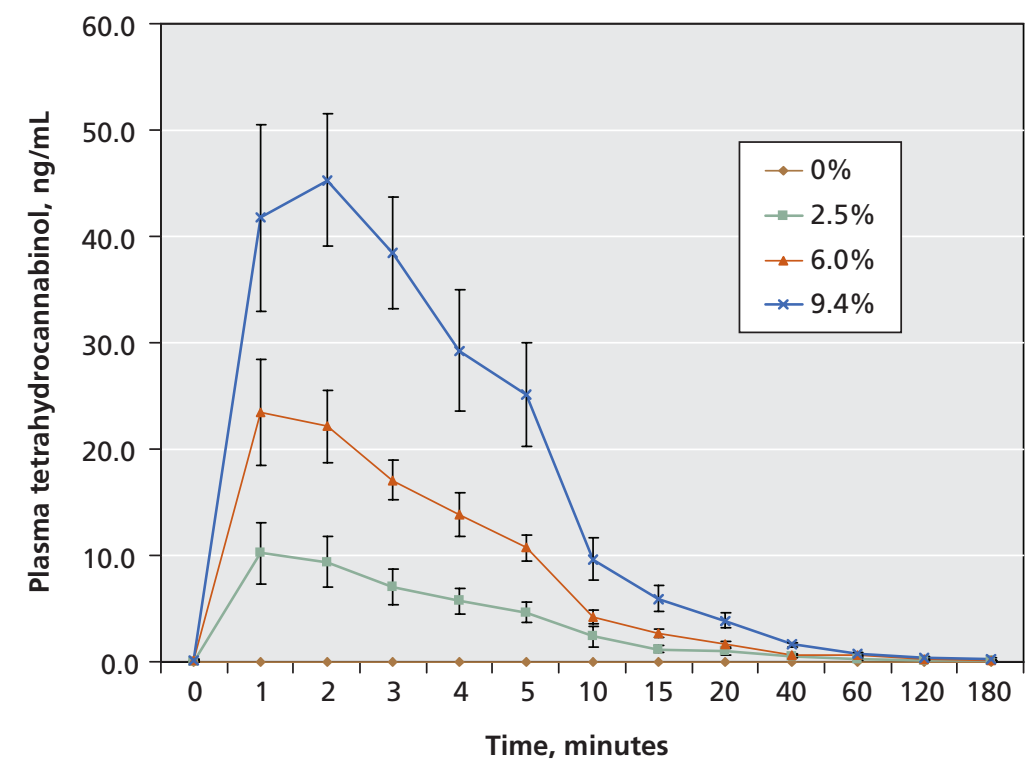

Figure 2: Levels of tetrahydrocannabinol (THC) in plasma after inhalation of a single dose. Data are presented as means and standard deviations. 
physicians, and we made a concerted effort to collect data on adverse events and describe short-term physiologic effects. The frequency of adverse events increased with tetrahydrocannabinol potency. Psychoactive effects did not result in participants withdrawing from the study. Euphoria or "high" was reported on only three occasions throughout the trial. There was no evidence of euphoria during the three hours following the first dose of each cycle regardless of tetrahydrocannabinol potency, possibly because plasma levels (mean $45 \mathrm{ng} / \mathrm{mL}$ ) did not reach levels found with recreational users $(>100 \mathrm{ng} / \mathrm{mL}){ }^{31}$

\section{Conclusion}

Our results support the claim that smoked cannabis reduces pain, improves mood and helps sleep. We believe that our trial provides a methodological approach that may be considered for further research. Clinical studies using inhaled delivery systems, such as vaporizers, ${ }^{32,33}$ are needed.

\section{This article has been peer reviewed.}

\section{Competing interests: None declared.}

Contributors: Mark Ware conceived and designed the study, and drafted the manuscript. Stan Shapiro, Jean-Paul Collet, Thierry Ducruet and Gary Bennett were involved in the conception and design of the study. Thierry Ducruet, Ann Robinson, Ann Gamsa and Thao Huynh were involved in the acquisition, analysis and interpretation of data. Tongtong Wang performed analysis of the data with support from Thierry Ducruet and Stan Shapiro. All of the authors were involved in the critical revision of the manuscript, and all of them approved the final draft submitted for publication.

Funding: This trial was supported by the Canadian Institutes of Health Research (grant no. JHM-50014). Financial support for pharmacokinetic assays was received from the Louise and Alan Edwards Foundation.

\section{REFERENCES}

1. Berger A, Dukes EM, Oster G. Clinical characteristics and economic costs of patients with painful neuropathic disorders. J Pain 2004;5:143-9.

2. Mendell JR, Sahenk Z. Clinical practice. Painful sensory neuropathy. $N$ Engl J Med 2003;348:1243-55

3. Moulin DE, Clark AJ, Gilron I, et al. Pharmacological management of chronic neuropathic pain - consensus statement and guidelines from the Canadian Pain Society. Pain Res Manag 2007;12:13-21.

4. Attal N, Cruccu G, Haanpaa M, et al. EFNS guidelines on pharmacological treatment of neuropathic pain. Eur J Neurol 2006;13:1153-69.

5. Mechoulam R. The pharmacohistory of Cannabis sativa. In: Mechoulam R, editors Cannabinoids as therapeutic agents. Boca Raton (FL): CRC Press; 1986. p. 1-19.

6. Meng ID, Manning BH, Martin WJ, et al. An analgesia circuit activated by cannabinoids. Nature 1998;395:381-3.

7. Ware MA, Gamsa A, Persson J, et al. Cannabis for chronic pain: case series and implications for clinicians. Pain Res Manag 2002;7:95-9.

8. Svendsen KB, Jensen TS, Bach FW. Does the cannabinoid dronabinol reduce central pain in multiple sclerosis? Randomised double blind placebo controlled crossover trial. BMJ 2004;329:253.

9. Rog DJ, Nurmikko TJ, Friede T, et al. Randomized, controlled trial of cannabis- based medicine in central pain in multiple sclerosis. Neurology 2005;65:812-9.

10. Nurmikko TJ, Serpell MG, Hoggart B, et al. Sativex successfully treats neuropathic pain characterised by allodynia: a randomised, double-blind, placebo-controlled clinical trial. Pain 2007;133:210-20.

11. Blake DR, Robson P, Ho M, et al. Preliminary assessment of the efficacy, tolerability and safety of a cannabis-based medicine (Sativex) in the treatment of pain caused by rheumatoid arthritis. Rheumatology (Oxford) 2005;45:50-2

12. Skrabek RQ, Galimova L, Ethans K, et al. Nabilone for the treatment of pain in fibromyalgia. J Pain 2008;9:164-73.

13. Ware MA, Doyle CR, Woods R, et al. Cannabis use for chronic non-cancer pain: results of a prospective survey. Pain 2003;102:211-6.

14. Clark AJ, Ware MA, Yazer E, et al. Patterns of cannabis use among patients with multiple sclerosis. Neurology 2004;62:2098-100.

15. Abrams DI, Jay CA, Shade SB, et al. Cannabis in painful HIV-associated sensory neuropathy: a randomized placebo-controlled trial. Neurology 2007;68:515-21.

16. Ellis RJ, Toperoff W, Vaida F, et al. Smoked medicinal cannabis for neuropathic pain in HIV: a randomized, crossover clinical trial. Neuropsychopharmacology 2009;34:672-80.

17. Wilsey B, Marcotte T, Tsodikov A, et al. A randomized, placebo-controlled, crossover trial of cannabis cigarettes in neuropathic pain. J Pain 2008:9:506-21.

18. Dworkin RH, Turk DC, Farrar JT, et al. Core outcome measures for chronic pain clinical trials: IMMPACT recommendations. Pain 2005;113:9-19.

19. Melzack R. The short-form McGill Pain Questionnaire. Pain 1987;30:191-7.

20. Parrott AC, Hindmarch I. The Leeds Sleep Evaluation Questionnaire in psychopharmacological investigations - a review. Psychopharmacology (Berl) 1980;71:173-9.

21. Shacham S. A shortened version of the Profile of Mood States. J Pers Assess 1983;47:305-6.

22. Hurst NP, Kind P, Ruta D, et al. Measuring health-related quality of life in rheumatoid arthritis: validity, responsiveness and reliability of EuroQol (EQ-5D). Br J Rheumatol 1997;36:551-9.

23. Chait LD, Burke KA. Preference for high- versus low-potency marijuana. Pharmacol Biochem Behav 1994:49:643-7.

24. Chait LD, Evans SM, Grant KA, et al. Discriminative stimulus and subjective effects of smoked marijuana in humans. Psychopharmacology (Berl) 1988;94:206-12.

25. Chait LD, Zacny JP. Reinforcing and subjective effects of oral delta 9-THC and smoked marijuana in humans. Psychopharmacology (Berl) 1992;107:255-62.

26. Dworkin RH, Turk DC, Wyrwich KW, et al. Interpreting the clinical importance of treatment outcomes in chronic pain clinical trials: IMMPACT recommendations. J Pain 2008;9:105-21.

27. Good Clinical Practice: Consolidated Guidelines. International Conference on Harmonisation of Technical Requirements for Registration of Pharmaceuticals for Human Use. E6(R1):1996; Switzerland. Available at: www.ich.org/cache/compo /276-254-1.html (accessed 2010 Aug. 18).

28. Backonja M, Beydoun A, Edwards KR, et al. Gabapentin for the symptomatic treatment of painful neuropathy in patients with diabetes mellitus: a randomized controlled trial. JAMA 1998;280:1831-6.

29. Richter RW, Portenoy R, Sharma U, et al. Relief of painful diabetic peripheral neuropathy with pregabalin: a randomized, placebo-controlled trial. J Pain 2005;6: 253-60

30. Azorlosa JL, Heishman SJ, Stitzer ML, et al. Marijuana smoking: effect of varying delta 9-tetrahydrocannabinol content and number of puffs. J Pharmacol Exp Ther 1992;261:114-22.

31. Grotenhermen F. Pharmacokinetics and pharmacodynamics of cannabinoids. Clin Pharmacokinet 2003;42:327-60.

32. Abrams DI, Vizoso HP, Shade SB, et al. Vaporization as a smokeless cannabis delivery system: a pilot study. Clin Pharmacol Ther 2007;82:572-8.

33. Zuurman L, Roy C, Schoemaker RC, et al. Effect of intrapulmonary tetrahydrocannabinol administration in humans. J Psychopharmacol 2008;22:707-16.

Correspondence to: Dr. Mark A. Ware, E19.145, Montréal General Hospital, 1650 Cedar Ave., Montréal QC H3G 1A4;

mark.ware@muhc.mcgill.ca 